\title{
BMJ Open Adapting the emergency first aid responder course for Zambia through curriculum mapping and blueprinting
}

\author{
Jennifer L Pigoga, ${ }^{1,2}$ Charmaine Cunningham, ${ }^{2}$ Muhumpu Kafwamfwa, ${ }^{3}$ \\ Lee A Wallis ${ }^{2}$
}

To cite: Pigoga JL, Cunningham C, Kafwamfwa M, et al. Adapting the emergency first aid responder course for Zambia through curriculum mapping and blueprinting. BMJ Open 2017;7:e018389. doi:10.1136/ bmjopen-2017-018389

- Prepublication history and additional material for this paper are available online. To view these files, please visit the journal online (http://dx.doi. org/10.1136/bmjopen-2017018389).

Received 27 June 2017 Revised 27 0ctober 2017 Accepted 3 November 2017

\section{CrossMark}

${ }^{1}$ Rollins School of Public Health, Emory University, Atlanta, Georgia, USA

${ }^{2}$ Division of Emergency Medicine, University of Cape Town, CapeTown, South Africa ${ }^{3}$ Mobile and Emergency Health Services, Zambian Ministry of Health, Lusaka, Zambia

Correspondence to Jennifer L Pigoga; jennigoga@gmail.com

\section{ABSTRACT}

Objectives Community members are often the first to witness and respond to medical and traumatic emergencies, making them an essential first link to emergency care systems. The Emergency First Aid Responder (EFAR) programme is short course originally developed to help South Africans manage emergencies at the community level, pending arrival of formal care providers. EFAR was implemented in two rural regions of Zambia in 2015 , but no changes were originally made to tailor the course to the new setting. We undertook this study to identify potential refinements in the original EFAR curriculum, and to adapt it to the local context in Zambia. Design The EFAR curriculum was mapped against available chief complaint data. An expert group used information from the map, in tandem with personal knowledge, to rank each course topic for potential impact on patient outcomes and frequency of use in practice. Individual blueprints were compiled to generate a refined EFAR curriculum, the time breakdown of which reflects the relative weight of each topic.

Setting This study was conducted based on data collected in Kasama, a rural region of Zambia's Northern Province.

Participants An expert group of five physicians practising emergency medicine was selected; all reviewers have expertise in the Zambian context, EFAR programme and/or curriculum development.

Results The range of emergencies that Zambian EFARs encounter indicates that the course must be broad in scope. The refined curriculum covers 54 topics (seven new) and 25 practical skills (five new). Practical and didactic time devoted to general patient care and scene management increased significantly, while time devoted to most other clinical, presentation-based categories (eg, trauma care) decreased.

Conclusions Discrepancies between original and refined curricula highlight a mismatch between the external curriculum and local context. Even with limited data and resources, curriculum mapping and blueprinting are possible means of resolving these contextual issues.

\section{INTRODUCTION}

Emergency care encompasses a range of time-sensitive health services provided for acute medical, surgical and obstetric conditions to avoid death or disability. Although

\section{Strength and limitations of this study}

- The study highlights the importance of tailoring medical education curriculums to local context.

- It adds to a limited evidence base surrounding the refinement of medical education curriculums in lowincome and middle-income countries.

- The curriculum mapping and blueprinting methodology presented in this study is likely useful in most low-resource settings.

- The translatability of the curriculum generated through this study is limited, as data were only collected from a single site in rural Zambia.

- These methods did not account for qualitative commentary data and community member input, which might have been useful in informing the final curriculum.

well embedded into the healthcare systems of many high-income countries, the establishment of emergency care in low-income and middle-income countries (LMICs) remains an ongoing challenge, despite the central role it can play in the health system. ${ }^{1-5}$ Even allowing for poor reporting mechanisms, ${ }^{6-8}$ it is clear that LMICs are burdened by the highest rates of injury and illness in nearly every category, ${ }^{9-13}$ and vulnerable populations within these nations are at particular risk. ${ }^{14-17}$ These emergencies come at high cost, directly affecting the psychosocial, health, productivity and economic status of LMICs. ${ }^{4} 13$ 18-23

While regular and timely access to medical care should be of utmost importance in LMICs, numerous barriers, including rural living and negative financial implications, prevent this from occurring in a manner envisaged by the longitudinal primary care model. ${ }^{124}$ As a result, emergency care is the first point of contact with the health system for a great many people worldwide (including the poor and uninsured in high-income countries). Emergency care systems have the potential to reduce deaths in LMICs by 
$54 \%^{24} 25$; the prehospital component alone is also highly effective, reducing trauma-related mortality by up to $25 \% .^{26}$

Prehospital emergency care systems modelled on those in high-income countries are unaffordable for most LMICs, which are in need of a less-expensive model. ${ }^{127}$ This model should be able to serve either as a foundation for prehospital care in areas where it does not exist or as a support system to help newer prehospital care systems grow into maturity. ${ }^{28}$ The Emergency First Aid Responder (EFAR) programme, which was developed in 2010 to meet the emergency care needs of low-resource areas in South Africa, satisfies these criteria. ${ }^{4}$ EFAR relies on community involvement, on the basis that training a large number of community members will increase the likelihood that an EFAR is present or near to any emergency that may occur. Through community-specific trainings, EFARs are taught to provide life-saving care in the interim before ambulance arrival. Similar short courses geared towards layperson responders have proven effective in other LMICs. ${ }^{29-33}$

Zambia is a lower middle-income Southern African nation of 16.2 million. ${ }^{34}$ It may be considered a fairly typical African LMIC: although the country is urbanising, the majority of Zambians continue to live in rural areas and below the poverty line. ${ }^{34}$ Maternal and infant mortality rates are high, ${ }^{35}$ and the majority of premature deaths are preventable, stemming from injuries and infectious disease. ${ }^{34}$ Emergency care systems in Zambia are insufficient, and there is no national ambulance service ${ }^{36}$ Most healthcare is public, provided collaboratively by the Zambian Ministry of Health and Zambian Defence Force, but the healthcare workforce remains inadequate. ${ }^{34}{ }^{36}$ In order to improve emergency care, as the Zambian Ministry of Health and Zambian Defence Force have stated they wish to do, a multifaceted approach needs to be taken. Providers must be trained and hospital care must be improved, but, in the meantime, Zambians must be empowered to handle emergencies on the community level. ${ }^{37}$

In a 2014 needs assessment, Zambians identified that a grassroots community response programme could facilitate the eventual formation of a strong and formal prehospital care system in their country. ${ }^{38}$ Motivated by this, the Zambian Ministry of Health and Zambian Defence Force implemented the EFAR programme in 2015 in two rural villages: Kasama and Nyimba. The programme uses community health centres to recruit participants and hold trainings. ${ }^{39}$ These centres are staffed by the Zambian Defence Force, but serve both military personnel and the civilians in the region. There has since been concern that the Zambian EFAR curriculum-which was not modified from the original South African programme-was not a good fit for the emergency care needs of rural Zambian communities. The Zambian setting differs from the South African one in many ways: it is rural, less violent, has less existing infrastructure, and overall different culture and lifestyles. All of these factors are likely to influence the types of emergencies seen, and yet, existing local resources and needs have not been reflected in the EFAR curriculum.

Most educators focus primarily on adapting medical education curriculums as science surrounding course content evolves. But, secondarily, it is also necessary to tailor curriculums to local needs and resources. This is especially important in LMICs, where resource levels and health systems infrastructure can vary drastically even within a region. Curriculum mapping is a method of spatially representing the components of a curriculum that allows for identification of gaps and overlaps in course content. ${ }^{40}{ }^{41}$ Curriculum mapping has become well accepted in the medical community in high-income countries as a means of keeping up with an ever-increasing knowledge base. It facilitates ongoing curricular evaluation, and rapid improvement and evolution, ${ }^{42}$ and has been shown to improve educational outcomes. ${ }^{41}$

In the case of the EFAR curriculum, the purpose of curriculum mapping was to align curricular elements (the topics and skills covered in the course) with the emergency care needs of the regional population. The map alone does not yield a weighted curriculum breakdown. Instead, it serves as a source of information for a second refinement process. Curriculum blueprinting, as defined by Coderre $e t$ al, builds off the map, yielding a quantified distribution of curricular topics. ${ }^{43}$ With expert input, curricular elements are weighted for both impact of learning the element and frequency with which the element is seen in the field. From the quantitative data that results, learning objectives and experiences can be revised. ${ }^{43}$ These two methods-curriculum mapping and course blueprinting-have revolutionised the way in which modern medical education is planned, taught and assessed. While commonplace in high-income countries, there is a little evidence surrounding the use of mapping and blueprinting in LMICs. An understanding of the importance of curriculum development has translated to some regions of sub-Saharan Africa, but implementing development methods has been noted as challenging in environments that already lack manpower and other resources. ${ }^{44}$ We believe that curriculum mapping and blueprinting could be an effective means of refining course context and scope, thus positively impacting the development of medical education in LMICs.

This study sought to use existing EFAR data and expert input to identify potential refinements and adapt the EFAR curriculum to Zambia.

\section{METHODS}

\section{EFAR site data collection and analysis}

Previous communications indicated that the EFAR patient run forms (PRFs) were being stored at the two Zambian Defence Force health centres where trainings had been held. All EFAR-patient interactions logged between July 2015 and June 2016 were collected, retrospectively up until March 2016 and then prospectively. 
Data included patient demographics, chief complaints, presentations and dispositions. No identifying information was collected. Data were entered into encrypted Microsoft Excel (Microsoft) spreadsheets onsite. Basic statistics were generated using SAS V.9.4 Software (SAS).

\section{Curriculum refinement}

\section{Selecting an expert group}

Conducting a successful curriculum refinement requires a group of experienced educators, topic opinion leaders and medical professionals. The group may be as small as three members for a short learning experience, but should grow in size as the complexity of the learning experience increases. ${ }^{45}$

A group of five was deemed appropriate for this study. Reviewers were identified via email. All were physicians practising emergency medicine. Reviewers were also required to have expertise in the Zambian context, the EFAR programme and/or curriculum development.

\section{Curriculum mapping}

The lead researcher generated two initial curriculum maps-one for course topics and another for skillsby mapping all curricular elements against all chief complaints (extracted from PRFs) in Microsoft Excel. Chief complaints were then matched to the existing EFAR curriculum by the lead researcher using a binary system. The relationship between each curricular element and chief complaint was directly explored. For example, the topic 'headache' was matched to the chief complaint 'hypoglycaemia/hyperglycaemia', but it was not matched to another chief complaint, 'difficulty in breathing'. 1 's related curricular elements that are relevant to the chief complaint, such as 'headache' to 'hypoglycaemia/ hyperglycaemia'. 0's were not believed to be pertinent to a chief complaint, such as 'headache' to difficulty in 'breathing'.

The expert group reviewed the initial curriculum maps, validating or changing the curricular elements that corresponded to a particular complaint. Continuing with our example, if a reviewer did not agree that the topic 'headache' corresponded to the chief complaint of 'hypoglycaemia/hyperglycaemia' (as headache was mapped by the lead researcher), then the reviewer indicated this by changing the cell score from 1 to 0 . Free text space was provided to add additional curricular elements (eg, a topic not included in the curriculum but that the reviewer felt was important for handling the given chief complaint) and other relevant commentary.

The individual reviewer sheets for topics and skills were compiled and summed (refer to online supplements S1 and S2). Scores ranged from 0 (none of the reviewers found the curricular element important in relation to the chief complaint) to 5 (all found it important). Where reviewers suggested additional curricular elements that related to a chief complaint, these were added to the compiled map and received a score of 1 . The recorded number of times EFARs were presented with each chief complaint was also added to the compiled map, for ease of reference in the blueprinting stage.

\section{Curriculum blueprinting}

The two compiled maps were given to the expert review panel, to allow them to gain a sense of (1) how relevant the group overall felt each topic or skill was in relation to the chief complaints and (2) how frequently chief complaints are seen in Kasama.

Informed reviewers were then asked to rank curricular elements. Reviewers called on their personal knowledge and data from the maps to score each topic twice-once for impact and a second time for frequency (table 1). Impact referred to usability in providing appropriate care for a patient presenting with a specific condition, while frequency related to how often the element might be used in practice. Both impact and frequency were given a rank between 1 and 3, with 1 being the least important/ frequent and 3 being the most important/frequent.

It should be noted that the definitions of impact and frequency vary slightly in relation to a curricular element that is a medical or traumatic condition (eg, a traumatic injury) versus something that can be classified as general knowledge (eg, the Good Samaritan law) or a skill (eg, the method of scene size-up). For the former scenario, impact is ranked based on how frequently the skill might be used in treating a condition. A reviewer will likely consider a traumatic injury to be serious and perhaps life threatening, and thus, would rank it as a 2 or 3 for

\begin{tabular}{|c|c|c|c|c|}
\hline Weight & Impact & & Frequency & \\
\hline $\begin{array}{l}\text { Topic/skill } \\
\text { is... }\end{array}$ & $\begin{array}{l}\text { Medical/traumatic } \\
\text { condition (eg, stroke) }\end{array}$ & $\begin{array}{l}\text { General knowledge or skill } \\
\text { (eg, healthcare system or } \\
\text { scene size-up) }\end{array}$ & $\begin{array}{l}\text { Medical/traumatic } \\
\text { condition (eg, stroke) }\end{array}$ & $\begin{array}{l}\text { General knowledge or } \\
\text { skill (eg, healthcare } \\
\text { system or scene size-up) }\end{array}$ \\
\hline 1 & Non-urgent & $\begin{array}{l}\text { Little use in providing } \\
\text { appropriate care }\end{array}$ & Rarely seen & Rarely used \\
\hline 2 & $\begin{array}{l}\text { Serious, but not immediately } \\
\text { life threatening }\end{array}$ & $\begin{array}{l}\text { Some use in providing care } \\
\text { appropriate care }\end{array}$ & Relatively common & Occasionally used \\
\hline 3 & Life-threatening emergency & $\begin{array}{l}\text { Extremely useful in providing } \\
\text { care }\end{array}$ & Very common & Frequently used \\
\hline
\end{tabular}


Table 2 An example of determining the relative weights of curricular elements

\begin{tabular}{llllll}
\hline Column no. $\mathbf{1}$ & $\mathbf{2}$ & $\mathbf{3}$ & $\mathbf{4}$ & $\mathbf{5}$ & $\mathbf{6}$ \\
\hline Curriculum topic or skill & Mean impact $(\mathrm{I})$ & Mean frequency $(\mathrm{F})$ & $\mathrm{IxF}$ & $\mathrm{IxF} / \Sigma(\mathrm{IxF})$ & $\mathrm{IxF} / \Sigma(\mathrm{IxF})] \mathrm{x} 100$ \\
Bandaging open wounds & 2.6 & 2.5 & 6.5 & 0.06 & $6 \%$ \\
\hline
\end{tabular}

Mean impacts and frequencies are tabulated across all reviewers for all curricular elements (columns 2 and 3 ). The products of these impacts and frequencies are calculated for each element (column 4). Then, the IxF for each individual element is divided by the sum of all of that elements' IxF values (the total of column 4) to generate a relative weighting for each element (column 5). Column 6 represents this weight in percentage form. In this example, the skill of bandaging open wounds would take up $6 \%$ of practical course time.

impact. Based on the frequency of chief complaints given in the curriculum map, traumatic injuries are common. A reviewer would then assign the frequency to a value of 3. General knowledge refers to topics that are not actually medical conditions, but rather, concepts that supplement an EFAR's ability to treat the conditions themselves. An example of this would be the topics covered under medical-legal aspects of care. Knowledge of the Good Samaritan law might be of little use in the actual provision of appropriate care, but it might be used relatively often. Thus, it might rank a 1 on impact and a 2 on frequency. In the context of skills, the impact and frequency definitions are similar. A reviewer may think that the primary patient assessment is a skill that's used in nearly every patient encounter, and thus assign it a 3 for frequency. The reviewer may also believe it to be extremely useful in providing care, yielding a 3 for impact. The ranking system is beneficial, as it is much more efficient to analyse quantitative data versus the alternative of qualitative commentary. From these rankings, curricular elements can be weighted to give a breakdown of the curriculum in terms of time spent on each.

The ranking sheets were compiled. A weighted score was calculated for each curricular element (table 2), which represents the proportion of course time that educators should aim to spend on this curricular element. Topics correlate to didactic time, while skills correlate to practical (hands-on) time.

\section{RESULTS \\ EFAR site data}

Data availability

EFAR PRFs were available at the Kasama site. No PRFs were available at the Nyimba site.

\section{Patient demographics}

One hundred and ten patients were seen by EFARs in Kasama from July 2015 to June 2016. Most $(61,56 \%)$ were male and adults $(92,84 \%$; defined as over 11 years). The majority were brought to the Kasama Zambian Defence Force clinic $(94,86 \%)$. Nearly all patients $(101,92 \%)$ were referred to higher care.

\section{Chief complaints}

Twenty-nine unique complaints were identified across medical and traumatic emergencies. When grouped based on aetiology, the most common chief complaint was known injury (39\%), followed by respiratory problems (19\%).

\section{Curriculum mapping}

Mapping yielded an additional seven topics and six skills, for a total of 54 topics and 26 skills.

The results of curriculum mapping are available in online supplements S1 and S2.

\section{Curriculum blueprinting}

Mean impact scores for topics ranged from 0.5 (religion, culture and tradition) to 3.0 (principles of first aid, airway, breathing and unconsciousness). Mean frequency scores ranged from 0.33 (religion, culture and tradition) to 3.0 (bleeding, fever and dehydration). Product scores ranged from 0.17 (religion, culture and tradition) to 8.40 (bleeding, fever and dehydration). Topics were assigned between 0.4 and $86.7 \mathrm{~min}$ of course time.

Mean impact scores for skills ranged from 1.6 (for defibrillation and documentation) to 3.0 (opening and maintaining the airway). Mean frequency scores ranged from 0.75 (defibrillation) to 2.5 (bandaging, mobile phone use, patient primary assessment and trauma assessment). Product scores ranged from 1.20 (defibrillation) to 6.50 (bandaging, mobile phone use, patient primary assessment and trauma assessment). Skills were assigned between 4 and $21.6 \mathrm{~min}$ of course time.

The results of curriculum mapping are available in online supplements S3 and S4.

\section{The refined EFAR curriculum}

The original curriculum had six modules, into which each of the topics and skills for the refined curriculum were categorised for ease of comparison (table 3).

\section{DISCUSSION}

Curriculum mapping and blueprinting were practical means of adapting the programme and improving contextual relevancy, and are likely translatable to similar programmes in other LMIC settings.

Significant changes were required for the Zambian EFAR programme to be contextually relevant. The original and refined curriculums share only a single similarity in distribution across their six modules: medical emergencies. One module-introduction and scene management-saw a significant increase in time and three modules-obstetrics and gynaecology, unconsciousness 
Table 3 Comparison of the modules included in the original and refined Emergency First Aid Responder curricula

\begin{tabular}{|c|c|c|c|c|c|c|c|c|c|}
\hline \multirow[b]{2}{*}{ Module } & \multirow[b]{2}{*}{ Content } & \multicolumn{4}{|c|}{ Original curriculum } & \multicolumn{4}{|c|}{ Refined curriculum } \\
\hline & & $\begin{array}{l}\text { Didactic } \\
\text { time } \\
\text { (hour) }\end{array}$ & $\begin{array}{l}\text { Practical } \\
\text { time } \\
\text { (hour) }\end{array}$ & $\begin{array}{l}\text { Total time } \\
\text { (hour) }\end{array}$ & $\begin{array}{l}\text { Total } \\
\text { time (\%) }\end{array}$ & $\begin{array}{l}\text { Didactic } \\
\text { time (hour) }\end{array}$ & $\begin{array}{l}\text { Practical } \\
\text { time } \\
\text { (hour) }\end{array}$ & $\begin{array}{l}\text { Total } \\
\text { time } \\
\text { (hour) }\end{array}$ & $\begin{array}{l}\text { Total } \\
\text { time (\%) }\end{array}$ \\
\hline $\begin{array}{l}\text { Environmental } \\
\text { emergencies }\end{array}$ & $\begin{array}{l}\text { Bites and stings, } \\
\text { electrocution, } \\
\text { drowning and } \\
\text { lightening }\end{array}$ & 0.0 & 0.0 & 0.0 & 0.0 & 0.5 & 0.0 & 0.5 & 2.9 \\
\hline $\begin{array}{l}\text { Obstetrics and } \\
\text { gynaecology }\end{array}$ & $\begin{array}{l}\text { Cord prolapse, } \\
\text { antepartum and } \\
\text { postpartum } \\
\text { haemorrhage and } \\
\text { emergency delivery }\end{array}$ & 2.0 & 1.1 & 3.1 & 18.9 & 0.1 & 0.2 & 0.3 & 1.9 \\
\hline $\begin{array}{l}\text { Introduction } \\
\text { and scene } \\
\text { management }\end{array}$ & $\begin{array}{l}\text { Overview of first } \\
\text { aid, ethical aspects, } \\
\text { scene assessment, } \\
\text { primary and } \\
\text { secondary patient } \\
\text { assessments, mass } \\
\text { casualty incidents } \\
\text { and infection } \\
\text { control }\end{array}$ & 2.0 & 1.3 & 3.3 & 20.3 & 5.1 & 2.9 & 8.0 & 48.9 \\
\hline $\begin{array}{l}\text { Medical } \\
\text { emergencies }\end{array}$ & $\begin{array}{l}\text { Stroke, seizure, } \\
\text { fever, dehydration, } \\
\text { poisoning, breathing } \\
\text { difficulty and shock }\end{array}$ & 2.0 & 1.3 & 3.3 & 20.3 & 2.5 & 1.3 & 3.8 & 23.0 \\
\hline
\end{tabular}

and near unconsciousness, and injuries-were deemphasised in the final curriculum. The environmental emergencies module remained an insignificant portion of the curriculum. The medical emergencies module likely remained similar due to the burdens of infectious and non-communicable diseases being relatively similar between Zambia and South Africa. ${ }^{46}$

Deemphasising the obstetric and injury sections was not predicted, given the well-documented burdens in Zambia. ${ }^{34}$ Obstetric and gynaecologic emergencies, such as complicated delivery or postpartum haemorrhage, lead to high maternal mortality rates in Zambia, ${ }^{34} 48$ but they were not seen by EFARs in our study. The reasons behind this are unknown: it may suggest that existing systems to handle obstetric and gynaecologic emergencies in the Kasama region are adequate, but could equally be due to EFARs feeling disempowered in such cases and therefore not responding. Similarly, injuries accounted for nearly $40 \%$ of EFAR chief complaints and reviewers are likely intimately aware of the local burden of injury. ${ }^{49} 50$ Trauma care reflected this, ranking consistently high in mapping and blueprinting. Yet, injury was deemphasised in the final curriculum. A likely explanation for this is that trauma care was actually overrepresented in the original EFAR curriculum due to the extremely large burden of trauma in South Africa in comparison to Zambia. ${ }^{4} 495152$ Further work is required to explore the mismatch in both fields.

Introduction and scene management saw a $242 \%$ increase in learning time. In the context of the EFAR programme's main goal-training laypeople to handle the emergencies at a basic level-this result can be seen as successful. EFARs should be spending more time focusing on introductory material that will help them to handle a variety of emergencies. These results parallel other layperson responder programmes, which also place emphasis on broad skills that can aid patients presenting with a range of conditions. ${ }^{29} 33$ While environmental emergencies were included in the original curriculum, they were not included in the course programme that was implemented. Therefore, a before-and-after comparison could not be made, and the total time devoted in the 
original curriculum was denoted as zero. The percentage of total time in the refined curriculum is only around $3 \%$, speaking to why it may not have been included in the first place: local and programmatic experts do not perceive it to be important.

We believe the refined curriculum will be effective in instructing Zambian EFARs, and in preparing them to manage the emergencies they are most likely to face. This study highlights that no two settings are the same: even between South Africa and Zambia, the course breakdown differs significantly. It is important to consider the context at the start, and to reconsider it at scheduled time intervals, as these LMIC regions are rapidly changing. A refinement process such as this should be used to ensure an appropriate and evolved curriculum is in place as any medical education programme expands.

The EFAR programme, and layperson first response systems in general, are cost-effective means of reducing morbidity and mortality in LMICs. ${ }^{2653}$ These short courses must train up people with minimal prior knowledge in a short span-typically 1 to 5 days. ${ }^{43}$ As such, course time must be maximised. Mapping and blueprinting can be leveraged to ensure that this occurs. Where curriculums exist, it allows updating of the curriculum to ensure it is context appropriate. Where no curriculum currently exists, programme developers might use these methods instead to generate an initial curriculum.

It has also proven challenging to identify methods that allow for adaption of programmes to other regions, while maintaining low cost. There are few appropriate strategies for designing educational programmes in LMICs and training community members. ${ }^{54}$ Current literature focuses on resource-heavy methods used in high-income countries, but these are unrealistic in LMICs. The curriculum refinement methods we describe are an efficient way of tailoring programmes to local needs, without heavy reliance on data collection and research personnel. Although the method has two stages, it is cost-effective and time-effective. Adaptations were easily made throughout the process as needed, from the size of the expert group to the definitions of impact and frequency for blueprinting.

Together, the EFAR model and curriculum refinement methods provide a flexible framework for development and expansion of layperson medical education programmes. These community-based programmes are vitally important to LMIC health systems development, and should be prioritised.

There are several limitations in this study. Based on original communications, we anticipated that data would be collected from two sites. One site did not have any data and the second had significantly fewer PRFs available than predicted. The sample size was sufficient, but additional data would give a clearer picture of the types of chief complaints EFARs are presented with. It is not uncommon to be without sufficient data sets in LMICs, ${ }^{6-8}$ which supports the importance of using methods such as mapping and blueprinting that rely on minimal data in addition to other factors, such as expert knowledge. While this limits translatability of curriculum itself across other LMIC regions, it does not hinder translatability of our conclusion: curriculum mapping and blueprinting are practical methods of refining educational programmes to increase contextual relevancy.

The expert group that conducted curricular reviews was limited in size and nature. While the group included only physicians with significant knowledge about the Zambian context, community members and past EFAR trainees, who may have a different expectation of the scope of the EFAR course, were not engaged. Laypersons would likely need to be included in future studies through a simpler process, such as focus groups; however, current literature provides minimal guidance on how to incorporate this qualitative data into a weighted curriculum.

Additionally, the study only included quantitative data. Written commentary collected from reviewers was not incorporated. As such, potentially useful and nuanced comments were not factored into the final weightings of the curriculum. In future iterations, developers should consider methodology that allows for the consideration of various sources of qualitative data in generating the final curriculum.

Results of the study are informing an improved curriculum to be introduced in-country alongside improved monitoring and evaluation methods later in 2017. Pedagogy for EFAR learners will be explored during implementation to ensure that the course content outline in the curriculum is effectively reaching EFAR learners. Ongoing data collection will monitor learning retention, facilitate assessment of EFAR sites and allow efficient curriculum refinement at scheduled time points in the future.

Acknowledgements The research team would like to thank the expert review group for their efforts. We would also like to extend our gratitude to Heike Geduld, without whose insight into curriculum development, this project would not have been possible.

Contributors JLP, MK, CC and LAW conceived the study and contributed to its design. JLP carried out data collection and analysis, and drafted the manuscript. All authors contributed to the manuscript's revision and approved the final version for submission.

Competing interests None declared.

Ethics approval Ethical approval was obtained by the Human Research Ethics Committees at both the University of Cape Town and the University of Zambia.

Provenance and peer review Not commissioned; externally peer reviewed.

Data sharing statement No additional data are available.

Open Access This is an Open Access article distributed in accordance with the Creative Commons Attribution Non Commercial (CC BY-NC 4.0) license, which permits others to distribute, remix, adapt, build upon this work non-commercially, and license their derivative works on different terms, provided the original work is properly cited and the use is non-commercial. See: http://creativecommons.org/ licenses/by-nc/4.0/

(C) Article author(s) (or their employer(s) unless otherwise stated in the text of the article) 2017. All rights reserved. No commercial use is permitted unless otherwise expressly granted. 


\section{REFERENCES}

1. Harris B, Goudge J, Ataguba JE, et al. Inequities in access to health care in South Africa. J Public Health Policy 2011;32(Suppl 1):S102-23.

2. Anthony DR. Promoting emergency medical care systems in the developing world: weighing the costs. Glob Public Health 2011;6:906-13.

3. Nelson BD, Dierberg K, Sćepanović M, et al. Integrating quantitative and qualitative methodologies for the assessment of health care systems: emergency medicine in post-conflict Serbia. BMC Health Serv Res 2005;5:14.

4. Sun JH, Wallis LA. The emergency first aid responder system model: using community members to assist life-threatening emergencies in violent, developing areas of need. Emerg Med J 2012;29:673-8.

5. A-Rahman NHA, Jacquet GA. The state of emergency care in the Republic of the Sudan. Afr J Emerg Med 2014;4:55-60.

6. Garg N, Hyder AA. Road traffic injuries in India: a review of the literature. Scand J Public Health 2006;34:100-9.

7. Holmes MD, Dalal S, Volmink J, et al. Non-communicable diseases in sub-Saharan Africa: the case for cohort studies. PLoS Med 2010;7:e1000244.

8. Fingerhut LA. International collaborative effort on injury statistics: 10-year review. Inj Control Saf Promot 2004;11:297-301.

9. Reynolds TA, Mfinanga JA, Sawe HR, et al. Emergency care capacity in Africa: a clinical and educational initiative in Tanzania. J Public Health Policy 2012;33(Suppl 1):S126-37.

10. Lopez A, Mathers C, Ezzati M, et al. Global burden of disease and risk factors. In: Measuring the global burden of disease and risk factors, 1990-2001. Washington, DC: New York Oxford University Press.

11. Parkin DM, Sitas F, Chirenje M, et al. Part I: cancer in indigenous Africans-burden, distribution, and trends. Lancet Oncol 2008;9:683-92.

12. International Diabetes Foundation. Diabetes atlas. Brussels, Belgium: International Diabetes Foundation, 2009.

13. Peden MMK, Sharma G. The injury chart book: a graphical overview of the global burden of injuries. Geneva: World Health Organization, 2002.

14. Mbugua PK, Otieno CF, Kayima JK, et al. Diabetic ketoacidosis: clinical presentation and precipitating factors at Kenyatta National Hospital, Nairobi. East Afr Med J 2005;82(12 Suppl):S191-6.

15. Desta T. Diabetic ketoacidosis in an addis abeba children's hospital. Ethiop Med J 1992;30:7-11.

16. Walker CL, Rudan I, Liu L, et al. Global burden of childhood pneumonia and diarrhoea. Lancet 2013;381:1405-16.

17. Number of deaths (thousands) - Data by country. Global health observatory data repository. Geneva, 2016.

18. Smigelsky M, Aten J, Gerberich S, et al. Cost of trauma in sub-saharan africa: review of origins, estimation methods and interventions: The Humanitarian Disaster Institute, 2012.

19. The global burden of disease: 2004 update. Geneva, Switzerland: World Health Organization, 2004:40-5

20. Schuurman N, Cinnamon J, Walker BB, et al. Intentional injury and violence in Cape Town, South Africa: an epidemiological analysis of trauma admissions data. Glob Health Action 2015;8:27016.

21. Mock CN, Abantanga F, Cummings $P$, et al. Incidence and outcome of injury in Ghana: a community-based survey. Bull World Health Organ 1999;77:955-64.

22. Seid M, Azazh A, Enquselassie F, et al. Injury characteristics and outcome of road traffic accident among victims at Adult Emergency Department of Tikur Anbessa specialized hospital, Addis Ababa, Ethiopia: a prospective hospital based study. BMC Emerg Med 2015:15:10.

23. Hamber B, Lewis S. An overview of the consequences of violence and trauma in south africa: centre for the study of violence and reconciliation, 1997.

24. Thind A, Hsia R, Mabweijano JR, et al. Essential surgery. disease control priorities in developing countries, 2015:246.

25. Kobusingye OC, Hyder AA, Bishai D, et al. Emergency medical systems in low- and middle-income countries: recommendations for action. Bull World Health Organ 2005;83:626-31.

26. Henry JA, Reingold AL. Prehospital trauma systems reduce mortality in developing countries: a systematic review and meta-analysis. J Trauma Acute Care Surg 2012;73:261-8.
27. Breman JG, Measham AR, Jamison DT, et al. Disease control priorities in developing countries. 2nd edn. Washington DC, 2006.

28. Hammerstedt H, Maling S, Kasyaba R, et al. World health assembly resolution 60.22. [corrected]. Ann Emerg Med 2014;64:461-8.

29. Jayaraman S, Mabweijano JR, Lipnick MS, et al. Current patterns of prehospital trauma care in Kampala, Uganda and the feasibility of a lay-first-responder training program. World J Surg 2009;33:2512-21.

30. Murad MK, Larsen S, Husum H. Prehospital trauma care reduces mortality. Ten-year results from a time-cohort and trauma audit study in Iraq. Scand J Trauma Resusc Emerg Med 2012;20:13.

31. Murad MK, Issa DB, Mustafa FM, et al. Prehospital trauma system reduces mortality in severe trauma: a controlled study of road traffic casualties in Iraq. Prehosp Disaster Med 2012;27:36-41.

32. Geduld H, Wallis $L$. Taxi driver training in Madagascar: the first step in developing a functioning prehospital emergency care system. Emerg Med J 2011;28:794-6.

33. Mock CN, Tiska M, Adu-Ampofo M, et al. Improvements in prehospital trauma care in an African country with no forma emergency medical services. J Trauma 2002;53:90-7.

34. WHO. Country cooperation strategy at a glance: Zambia. Geneva: WHO, 2014.

35. WHO. Statistical profile Geneva: global health observatory. Zambia: WHO, 2015.

36. Human resources for health country profile: Zambia, 2010 https:// faculty.mu.edu.sa/public/uploads/1360246558.0499human\% 20resource104.pdf Africa Health Workforce Observatory.

37. National stakeholders consultative meeting on emergency health services: action plan Lusaka. Zambian Ministry of Health, 2012.

38. Broccoli MC, Cunningham C, Twomey M, et al. Communitybased perceptions of emergency care in Zambian communities lacking formalised emergency medicine systems. Emerg Med J 2016;33:870-5

39. Kim YM, Banda J, Kanjipite W, et al. Improving performance of Zambia defence force antiretroviral therapy providers: evaluation of a standards-based approach. Glob Health Sci Pract 2013;1:213-27.

40. Harden RM. AMEE Guide No. 21: curriculum mapping: a tool for transparent and authentic teaching and learning. Med Teach 2001;23:123-37

41. Husted K. Curriculum mapping: a tool to help you track what you teach. Teaching Theatre 2000;11:10-12.

42. Essary AC, Statler MP. Using a curriculum map to link the competencies for the PA profession with assessment tools in PA education. J Physician Assist Educ 2007;18:22-8.

43. Coderre S, Woloschuk W, McLaughlin K. Twelve tips for blueprinting. Med Teach 2009;31:322-4.

44. Kiguli-Malwadde E, Kijjambu S, Kiguli S, et al. Problem based learning, curriculum development and change process at faculty of medicine, Makerere University, Uganda. Afr Health Sci 2006;6:127-30.

45. Mcleod P, Steinert Y. Twelve tips for curriculum renewal. Med Teach 2015;37:232-8.

46. World Health Organization. South Africa statistics summary (2002 - present). Global health observatory country views. Geneva: World Health Organization, 2016

47. World Health Organization. Zambia statistics summary (2002 present). Global health observatory country views. Geneva: World Health Organization, 2016.

48. Gabrysch S, Cousens S, Cox J, et al. The influence of distance and level of care on delivery place in rural Zambia: a study of linked national data in a geographic information system. PLoS Med 2011;8:e1000394.

49. GBD Profile: Zambia. Global burden of diseases, injuries, and risk factors study 2010. Seattle: Institute for Health Metrics and Evaluation, 2010.

50. Murray CJ, Lopez AD. Mortality by cause for eight regions of the world: global burden of disease study. Lancet 1997;349:1269-76.

51. Ted L. Still marginal: crime in the coloured community. SA Crime Quarterly 2004;7:6.

52. Hardcastle TC, O'osthuizen G, Clarke D, et al. Trauma, a preventable burden of disease in South Africa: review of the evidence, with a focus on KwaZulu-Natal. SA Health Review 2016;2016:179-89.

53. Razzak JA, Kellermann AL. Emergency medical care in developing countries: is it worthwhile? Bull World Health Organ 2002;80:900-5.

54. Greysen SR, Dovlo D, Olapade-Olaopa EO, et al. Medical education in sub-Saharan Africa: a literature review. Med Educ 2011;45:973-86. 